\title{
Osteoblasts MC3T3-E1 Response in 2D and 3D Cell Cultures Models to High Carbon Content CoCr Alloy Particles. Effect of Metallic Particles on Vimentin Expression
}

BT Pérez-Maceda ${ }^{1}$, ME López-Fernández ${ }^{1}$, I. Díaz ${ }^{2}$, A. Kavanaugh ${ }^{3}$, F. Billi ${ }^{3}$, ML Escudero $^{2}$, MC García-Alonso $^{2}$, \& RM Lozano ${ }^{1}$

${ }^{1}$ Cell-Biomaterial Recognition Lab. Department of Cell and Molecular Biology. Centro de Investigaciones Biológicas (CIB-CSIC). Ramiro de Maeztu 9, 28040 Madrid, Spain

${ }^{2}$ Department of Materials Engineering, Degradation and Durability. Centro Nacional de Investigaciones Metalúrgicas (CENIM-CSIC). Avda. Gregorio del Amo 8, 28040 Madrid, Spain.

${ }^{3}$ Department of Orthopaedic Surgery, David Geffen School of Medicine, University of California Los Angeles, Orthopaedic Hospital Research Center. 615 Charles E. Young Dr. South, Room 450A Los Angeles, CA 90095-7358, USA

Correspondence: RM Lozano, Cell-Biomaterial Recognition Lab. Department of Cell and Molecular Biology. Centro de Investigaciones Biológicas (CIB-CSIC). Ramiro de Maeztu 9, 28040 Madrid, Spain. E-mail: rlozano@cib.csic.es

Received: April 11, 2017

Accepted: April 26, 2017

Online Published: August 10, 2017

doi:10.5539/jmsr.v6n4p41

URL: https://doi.org/10.5539/jmsr.v6n4p41

\begin{abstract}
The study of the biocompability of the metallic materials is a priority treating to avoid the osteolysis and aseptic loosening of prosthesis. Wear debris is considered one of the main factors responsible for aseptic loosening of orthopedic endoprostheses. We examined the response of mouse osteoblasts MC3T3-E1 to high carbon cobalt-chrome ( $\mathrm{HCCoCr}$ ) particles obtained a) from wear-corrosion assays on a pin-on-disk tribometer using as pair an alumina ball and a disc of a $\mathrm{HCCoCr}$ alloy, and b) $\mathrm{HCCoCr}$ bulk particles obtained by nitrogen gas atomization from an alloy used in clinic for prostheses application. Mitochondrial activity and lactate dehydrogenase activity assayed in 2D and 3D osteoblasts cell culture models were used to evaluate the cellular response to size, shape, and chemical composition of the metallic particles. 2D cell model was used to study the direct interaction of cells with particles and 3D cell cultures was used to more closely mimic in vivo conditions. The results showed that vimentin was overexpressed in the $2 \mathrm{D}$ osteoblasts cultures in presence of metal particles. This might be related to the appearance of pseudotumor in the peri-prosthetic vicinity described in some implanted patients.
\end{abstract}

Keywords: $\mathrm{CoCr}$, wear particles, biocompatibility, 3D and 2D osteoblasts cell culture, Metal-on-Metal

\section{Introduction}

In recent years total hip replacement with loss of function has become an important concern in human health (Knight, Aujla, \& Biswas, 2011; Holzwarth \& Cotogno, 2012). According to the Agency for Healthcare Research and Quality more than 285000 total hip arthroplasties (THA) are performed each year in the United States (Bitar \& Parvizi, 2015). Based on number of THA performed per 100.000 citizens, Germany is on the top on the list (296 THA/100.000), followed by Switzerland (287/100.000) and Belgium (240/100.000) (Bitar \& Parvizi, 2015). This number reaches a 184 and 194 THA per each 100.000 people in United States and United Kingdom, respectively (Bitar \& Parvizi, 2015). The number of THA performed in the industrialized countries is increasing not only because of a more physically active elderly population but also due to a young population with an active life style that suffer from incapacitating joint diseases (Holzwarth \& Cotogno, 2012).

The most prevalent clinical substitution for THA is given by use of metal-on-polyethylene joint replacement that has shown good, cost-effective and predictable results for decades (Knight, Aujla, \& Biswas, 2011). However, excessive wear of polyethylene produced by the mobile articulating bearing causes the production of particles believed to be the major cause of progressive bone loss or osteolysis (Jacobs et al., 2001) and subsequent loosening of prosthesis due to the mechanical instability of the prosthetic components (Doorn, Campbell, \& 
Amstutz, 1996). This problem has strongly driven the use of other alternative material combinations such as metal-on-ceramics or metal-on-metal (MoM) to improve the wear resistance in joint prosthesis (Bitar \& Parvizi, 2015). The risks of fracture associated with the use ceramic bearing have motivated the interest in MoM bearings (Bitar \& Parvizi, 2015). Cobalt-chrome alloys (CoCr) are commonly used for the MoM hip joints due to their substantially low corrosion and wear rates (Silva, Heisel, \& Schmalzried, 2005; Yan, Neville, Dowson, \& Williams, 2006; Yan, Neville, \& Dowson, 2007). Their excellent corrosion resistance relies on the formation of very stable, continuous, highly adherent and protective passive film on the metallic surface (Milosev, 2012). This passive film prevents degradation of the alloys as is one of the kinetic barriers preventing implant corrosion (Arnholt et al., 2016). However, due to wear, electrochemical dissolution, or a combination of the 2 processes, micro and nanometric sizes wear particles are still produced and metallic ions are released from the prosthesis of the implanted patients (Billi et al., 2009; Hosman et al., 2010; Arnholt et al., 2016). Catelas et al. (2003) have reported the necessity to carry out in vitro studies of the effects of these wear particles rather than the effect of CoCrMo particles on tissue response. In our aim, to get a better understanding of $\mathrm{CoCr}$ alloys as biomaterial for MoM applications and reach a better comprehension of the interaction of metallic particles with cells in contact with the implant prosthesis, cellular and biochemical studies have been carried out in mouse osteoblasts MC3T3-E1. To accomplish these goals, a comparative study was done using as control bulk particles obtained from Sandvick Bioline F1537 used in clinic as alloy for prostheses application, as hip, knee, and shoulder as is claimed by Sandvick in the Bioline F1537 material datasheet, and wear particles from a $\mathrm{HCCoCr}$ alloy obtained from pin-on-disc corrosion wear test as a method selected to generate material wear particles.

The effects of particles described above on osteoblasts cell response were assessed by 2D and 3D cell cultures. The 2D assay provides mainly information about the events that takes place at the cell-particle interface (Arnholt et al., 2016) and the 3D cell culture is a model considered close to tissue architecture where multiple interactions between cell-cell and cell-extracellular matrix take place, and diffusion and substances transports mechanisms play an important role (Lee et al., 2009). Additionally, 3D cell cultures also create a cellular environment that promotes cellular differentiation and tissues organization that does not occur in 2D cell cultures (Huh, Hamilton, \& Ingber, 2011).

Differences in size, shape and surface chemistry between bulk and wear $\mathrm{CoCr}$ particles considered in this study could account for significant changes on osteoblasts cell response, i.e. in biocompatibility, degree of damage of the plasma membrane as well as in vimentin expression. Vimentin, a $57 \mathrm{kDa}$ type III intermediate filament protein responsible for architecture of cytoplasm, is implicated in inflammatory response and its over-expression has been involved in tumor processes (Mitra, 2014; Satelli \& Li, 2011). The results obtained in the present work support the hypothesis that the chemical composition of wear particles from the $\mathrm{CoCr}$ alloys, mainly produced by disruption of the passivation layer rich in metallic oxides, their snowflake shape together with higher proportion of smaller size particles compared to $\mathrm{HCCoCr}$ bulk particles, could be the cause of the overexpression of vimentin. The overexpression of this protein detected in the presence of wear particles was discussed in this study and its relation with the formation of granulomatous pseudotumors described in some MoM THA (Satelli \& Li, 2011; Hart et al., 2012).

\section{Materials and Methods}

\subsection{CoCr Metallic Particles}

Metallic wear particles were obtained from wear-corrosion assays carried out in pin-on-disk micro-test equipment with an integrated homemade electrochemical cell (3-electrode cell). A disc of $38 \mathrm{~mm}$ diameter and 4 $\mathrm{mm}$ thickness of a high carbon $\mathrm{CoCr}$ alloy (hereafter $\mathrm{HCCoCr}$ ) and an alumina ball of $6 \mathrm{~mm}$ diameter were used as disk and counterpart or pin, respectively. The elemental composition of $\mathrm{HCCoCr}$ alloy, in agreement to the ASTM F75 standard, was as followed: Cr: $29.4 \%$; Mo: $6.4 \%$; Mn: $0.7 \%$; Si: 0.7\%; C: $0.22 \%$; N: $0.16 \%$; Fe: $0.16 \%$; Ni: $0.1 \%$; Al: $0.01 \%$; W: 0.03\%; P: $0.001 \%$; S: $0.004 \%$; y Co: $62.115 \%$. "Double heat-treated" $\mathrm{HCCoCr}$ alloy disks, i.e. solution treatment (ST) followed by hot isostatically pressing (HIP), were obtained from Biomet. The sample preparation consisted of grinding on $\mathrm{SiC}$ paper, followed by mechanical polishing with $3 \mu \mathrm{m}$ diamond paste. Before wear-corrosion tests, the $\mathrm{HCCoCr}$ discs and alumina ball were washed with double distilled water and then cleaned in an ultrasonic ethanol bath for $10 \mathrm{~min}$. The alumina ball was placed in a pin plastic holder and fixed on the load cell. After mounting the HCCoCr disc and the counterpart in the tribometer, a $0.9 \%$ sodium chloride solution was poured into the electrochemical cell and temperature was set and maintained during the assay at $37 \pm 1{ }^{\circ} \mathrm{C}$. Low normal load of $5 \mathrm{~N}$ was applied on the counterpart. The frictional force was measured by means of a piezo-electric force transducer. A rotating motor at a rotation rate of $120 \mathrm{rpm}$ provided the working electrode motion. When rotation was applied, the end of the alumina ball drew wear track $\left(10 \mathrm{~mm}\right.$ in diameter) on the $\mathrm{HCCoCr}$ surface. The wear-corrosion assays were analyzed after $10^{6}$ cycles, 
simulating the wear produced by a person walking for 1 year (Pourzal et al., 2011). Particles produced under wear-corrosion of $\mathrm{HCCoCr} / \mathrm{alumina}$ couple were collected in the electrochemical cell. This type of set-up designed for wear-corrosion tests under electrochemical control, as is described in the studies of wear-corrosion processes (Leandre Casabán \& Igual Muñoz, 2011; Figueiredo-Pina, Matos Neves, \& Bandarra das Neves, 2011).

In addition, the influence of $\mathrm{HCCoCr}$ bulk particles on biocompatibility was also studied considering two different objectives: to be used as control material and as an attempt to study those cases where the wear produced is able to detach material from the core of the alloy. HCCoCr bulk particles obtained by nitrogen gas atomization, were kindly supplied as a dry black powder by Sandvick (Osprey Ltd England) from Sandvick Bioline F1537. The elemental composition of HCCoCr bulk particles was as follows: Cr: $28.6 \%$; Mo: $6.4 \%$; Mn: $0.93 \%$; Si: 0.66 \%; C $0.25 \%$; N $0.20 \%$; Fe: 0.093; Ni: $0.069 \%$; Al: $0.010 \%$; W: 0.010\%; P: 0.009 \%; S: $0.003 \%$; B: $0.001 \%$ y Co: $62.765 \%$.

Tribometer test and the bulk particles dispersed in distilled water were rotated end-over-end at 28 rpm for 24 hours at room temperature to evenly disperse the particles in solution. Finally, an aliquot of these solutions was sonicated several consecutives times for one minute immediately before size particles characterization was performed.

\subsection{Granulometry and Morphology of Metallic Particles}

Granulometric analysis of metallic particles obtained in the tribometer assays (wear particles) and by nitrogen gas atomization (bulk particles) was evaluated by laser diffraction using the mastersizer 3000 particle size analyzer.

The morphology of metallic particles was studied with a field emission scanning electron microscope (FE-SEM) (Supra VP-40; Zeiss, Peabody, MA) at a voltage of $15 \mathrm{kV}$ and chemically analyzed by means of Energy-dispersive spectroscopy (EDS) analysis (Thermo Ultradry feature sizing system; Thermo Electron Scientific Instruments, Madison, WI). In order to do this, metallic particles were first deposited by the protocol developed by Billi et al. for recovering metallic particles (Billi et al., 2012). This is a procedure that allows removing organic and inorganic impurities from metallic particles dispersed in liquid media based on density gradient centrifugation. Therefore, during centrifugation and according to the protocol, particles were passed through the layer of wash solution and the metal-selective high-density layer. This leads to well-dispersed particles deposited onto a $5 \mathrm{~mm} \times 5 \mathrm{~mm}$ featureless display silicon wafer (Ted Pella, Inc, Redding, CA, USA) coated with a monolayer of marine mussel glue (Cell-TakTM; BD Biosciences, San Jose, CA, USA). The silicon wafer was then coated with $10 \AA$ iridium.

\subsection{Particles Handling for Cell Culture Assays}

Particles were weighted, UV sterilized and resuspended in sterile bi-distillated water and maintained in aliquots at $-20{ }^{\circ} \mathrm{C}$ until use. Just before using them, particles were thawed and vigorously mixed with a vortex and resuspended and diluted in Dulbecco's Modified Eagle Medium (DMEM 41966; Gibco, BRL) supplemented with $10 \%$ heat-inactivated fetal bovine serum (FBS; Gibco, BRL) and with a mixture of antibiotics (penicillin at 100 units $/ \mathrm{ml}$ and streptomycin at $100 \mu \mathrm{g} / \mathrm{ml}$, Gibco, BRL), named as complete cell culture medium, at a concentration of $20 \mathrm{mg} / \mathrm{ml}$, that was used as stock solutions for preparing the particles concentration tested in different cell assays. Vigorous vortex was needed in all experimental steps that required particles manipulation to assure in each sample a polydisperse distribution of particles.

\subsection{Cell Line}

Osteoblasts MC3T3-E1 mouse cell line was obtained from DSMZ Human and Animal Cell Bank and was selected for better represent the cellular context where the osteoarticular prosthesis is implanted. MC3T3-E1 is a murine cell line from the calvaria used as a bone cell model (Quarles et al., 1992). Osteoblasts cell line was cultured in Dulbecco's Modified Eagle Medium (DMEM 41966; Gibco, BRL) supplemented with 10\% heat-inactivated fetal bovine serum (FBS; Gibco, BRL) and with a mixture of antibiotics (penicillin at 100 units $/ \mathrm{ml}$ and streptomycin at $100 \mu \mathrm{g} / \mathrm{ml}$, Gibco, BRL) and cells were used for culture assays between pass 4 and 15 .

\subsection{Osteoblasts 2D Cell Culture Assays}

To evaluate the effect of HCCoCr particles on cell cultures, MC3T3-E1 cells were seeded on a 96-well culture plates at a cell density of $2 \times 10^{5}$ cells $/ \mathrm{ml}$. In all cell cultures assays, a final volume of $100 \mu 1$ of cells suspension in complete cell culture medium was added to each well. After 24 hours in culture, cell media were removed and renewed by $100 \mu \mathrm{l}$ of a freshly solution of complete cell culture medium containing the following concentrations 
of HCCoCr particles: $0,0.5,1$ and $2 \mathrm{mg} / \mathrm{ml}$. Cell cultures were maintained for 72 hours in a cell culture chamber at $37^{\circ} \mathrm{C}$ and $5 \% \mathrm{CO}_{2}$. Incubation time was selected based on the set-up of cell cultures assays for metallic particles studies carried out in the lab.

\subsection{Osteoblasts $3 D$ Cell Culture Assays}

For 3D cell culture, CellCeram scaffdex ceramic scaffolds were used (Ref.- Scaffdex CM0002-4.5 mm diameter, Finland). CellCeram scaffolds are made of bioabsorbable hydroxyapatite and $\beta$-tricalciumphosphate containing $60 \%$ hydroxyapatite and $40 \% \beta$-tricalcium phosphate, a composition and structure similar to bone. CellCeram has a foam structure with average porosity of $83 \%$. Average pore size is $200-400 \mu \mathrm{m}$ with overall range of $100-800 \mu \mathrm{m}$. It also contains some microporosity and interconnected pores. CellCeram scaffolds of $4.5 \mathrm{~mm}$ diameter were placed on a 96-well cell culture plates and wetted with $100 \mu 1$ cell culture medium for 24 hours. Thereafter, cell culture medium was aspirated and cells at a density of $2 \times 10^{5}$ cells $/ \mathrm{ml}$ in complete cell culture medium were seeded on scaffolds and maintained in culture for 24 hours before exposition to HCCoCr particles. The effect on cell response of different doses of HCCoCr particles $(0,0.5,1$ and $2 \mathrm{mg} / \mathrm{ml})$ was evaluated on 3D osteoblasts cell cultures after 72 hours.

Scaffolds cryosem images were taken at the electronic microscopy facility at The Instituto de Ciencias Agrarias (ICA-CSIC) in a scanning electron microscope Zeiss DSM 960, equipped with an energy dispersive X-ray microanalysis Link ISIS Oxford and a backscattered electron detector with four diodes from KE Developments. The scanning microscope was equipped with a system for preparation and observation of frozen samples, Cryotrans CT-1500 Oxford. This equipment allows the observation of cellular structures and the water present in the samples. This procedure avoids the drying or dehydration processes in biological samples that are hydrated in its natural state that allow the observation of the sample as it is at the specific experimental time.

\subsection{Osteoblasts Mitochondrial Activity Measurement}

To evaluate the effect of the $\mathrm{HCCoCr}$ particles on mitochondrial activity of cell cultures exposed to the different particles concentrations, the reduction of the WST-1 reagent (4-[3-4-iodophenyl)-2-(4-nitro-phenyl)-2H-5-tetrazolio]-1,3-benzene disulfonate (Roche Diagnostics GmbH, Mannheim, Germany)) was measured. The mitochondrial activity measurement is directly proportional to the number of metabolically active cells in culture. After 72 hours, $10 \mu \mathrm{l}$ of the cell proliferation kit reagent WST-1 was added to each well containing $100 \mu \mathrm{l}$ of fresh cell culture medium, and the mixture was incubated inside the cell culture incubator. After incubation, $100 \mu \mathrm{l}$ of each reaction mixture was transferred to a 96 -well cell plate, and the absorbance of the samples was measured as differential absorbance, $415 \mathrm{~nm}$ minus $655 \mathrm{~nm}$, in an iMark microplate absorbance reader (Bio-Rad, CA, USA), using as a blank the absorbance given by complete cell culture medium. All experiments were carried out in triplicate.

\subsection{Osteoblasts Measurement of Lactate Dehydrogenase Activity}

To evaluate and quantify the effect of HCCoCr particles on cell death and cell lysis, lactate dehydrogenase (LDH) activity was measured in the supernatants of cell cultures by an enzymatic assay using the Cytotoxicity Detection $\mathrm{Kit}^{\text {plus }}$ (Roche Diagnostics GmbH, Mannheim, Germany). Supernatants were collected from cell culture after being exposed for 72 hours to the different $\mathrm{HCCoCr}$ particles concentrations and were centrifuged for 5 minutes at 1024g. The enzymatic assays were performed according to the LDH kit protocol provided by Roche Diagnostics. Complete cell culture medium was used as a control for absorbance base line. LDH activity was measured based on differential absorbance, $490 \mathrm{~nm}$ minus $655 \mathrm{~nm}$, in an iMark microplate absorbance reader (Bio-Rad, CA, USA). LDH catalyzes the conversion of lactate to pyruvate, reducing $\mathrm{NAD}^{+}$to $\mathrm{NADH} / \mathrm{H}^{+}$, which is used by the catalyst to reduce a tetrazolium salt to a formazan salt, which is responsible for the change in absorbance at $490 \mathrm{~nm}$. Quantification of LDH activity is used as an indicator of plasma membrane damage, as is a stable cytoplasmic enzyme that is present in all cells and is rapidly release into the cell culture supernatant when the plasma is damage and is used as a sign of cell death. All experiments were carried out in triplicate.

\subsection{Detection of Vimentin by Confocal Microscopy in MC3T3-E1 Osteoblasts Cell Cultures}

MC3T3-E1 osteoblasts were seeded on sterile glass cover slips in a volume of $1 \mathrm{ml}$ of complete cell culture medium on a 12-well culture plates at a cell density of $2 \times 10^{5}$ cells $/ \mathrm{ml}$. After 24 hours, the medium was changed and $1 \mathrm{ml}$ of fresh complete medium solution containing $\mathrm{HCCoCr}$ particles was added at the following concentrations: $0,0.5,1$ and $2 \mathrm{mg} / \mathrm{ml}$. After 72 hours in culture vimentin immunodetection assays were performed. Cells were fixed with cool methanol and incubated with 2\% Fetal Bovine Serum in Phosphate Buffer Saline (FBS-PBS) to block nonspecific binding of the primary antibody. A 1:1000 dilution of anti-vimentin antibody (mouse monoclonal anti-mouse; Cat. No. V5255; Sigma-Aldrich, St. Louis, MO, USA) in 2\% 
FBS-PBS was used as primary antibody and incubation was lasted for 1 hour at room temperature. After three 5 minutes wash-steps with PBS, a 1:400 dilution of Alexa-Fluor 488 dye anti-mouse (Cat. No. A11001; Molecular Probes) in a solution of $2 \%$ FBS-PBS was used as secondary antibody and incubation was lasted for 1 hour at room temperature in darkness. Afterwards, Hoechst 33258 reagent (Sigma-Aldrich, St. Louis, MO, USA), a dye that binds to DNA (Doyle, Griffiths, \& Newell, 1995), was added for cell nuclei staining by incubation with 2 $\mu \mathrm{g} / \mathrm{ml}$ Hoechst in PBS for 10 minutes at room temperature in darkness followed by three 5 minutes wash-steps with PBS. Afterwards, PBS was removed and $1 \mathrm{ml}$ of sterilized distillated water was added and glass cover slips were carefully mounted in slides adding $7 \mu \mathrm{l}$ of Mowiol mounting medium (4-88 Calbiochem). After staining, cells fluorescence was examined by a LEICA SP5 in a Confocal Scanning Microscopy equipped with a 63X objective (Confocal CIB facility). The fluorescence of Alexa-Fluor 488 dye was excited at $488 \mathrm{~nm}$ and measured between 500-548 $\mathrm{nm}$ and visualized as confocal microscopy images as green fluorescence. Hoechst 33258 fluorescence was excited at $405 \mathrm{~nm}$ and measured between $415-485 \mathrm{~nm}$ and was visualized in confocal microscopy images as blue fluorescence.

\section{Results}

\subsection{Particles Analysis}

A detail of the shape of wear and bulk particles is observed by scanning electron microscopy in Figure 1. Metallic particles obtained from both experimental procedures, wear assays and gas atomization, showed differences in shape. Wear particles (Figure 1a) showed an irregular shape with a rough contour that gives the appearance of snowflake to particles. Heterogeneity in particle size as aggregates with different dimensions was observed. In contrast, bulk particles had round shape, were well dispersed and showed a quite homogeneous size distribution.

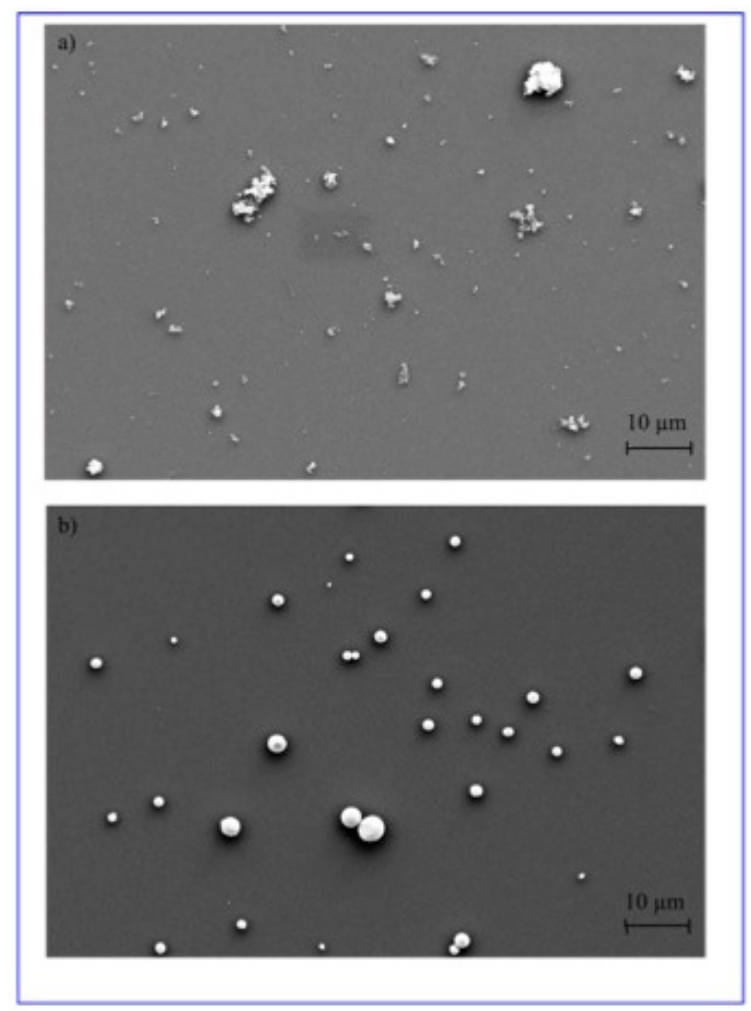

Figure 1. SEM images showing metallic particle morphologies: a) wear particles obtained from the tribometer assay and b) bulk particles obtained by gas atomization

Particle size seemed to be dependent on the method used to obtain them, as smaller particle size was sighted in the wear sample. Particle size distribution was further quantitatively analyzed by granulometric analysis as previously described in the Materials and Methods section. Granulometric analysis of both samples showed particles that ranged from above $>0.25 \mu \mathrm{m}$ up to $>10 \mu \mathrm{m}$ (Figure 2). It is particularly remarkable the differences 
in particles size distribution between the two samples as an homogeneous size distribution was observed in the case of the bulk particle samples. Particles in the $0.5 \mu \mathrm{m}$ to $2.5 \mu \mathrm{m}$ size range represented $90.9 \%$ of the bulk particle samples but only $52.8 \%$ of the wear particle samples. No particles of $0.25 \mu \mathrm{m}$ or smaller were observed in both type of samples and no particles $>5 \mu \mathrm{m}$ were detected in the bulk particles samples.

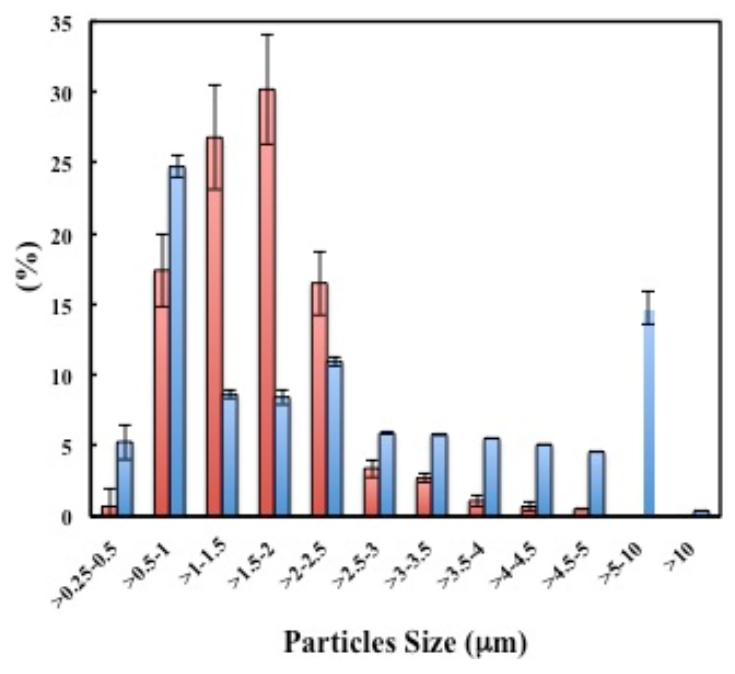

Figure 2. Granulometric analysis of metallic particles. Blue bars: wear particles and Red bars: bulk particles.

In order to carry out a comparative analysis between samples, granulometric results were divided as follow: $>0.25$ to $1 \mu \mathrm{m} ;>1$ to $2.5 \mu \mathrm{m} ;>2.5$ to $5 \mu \mathrm{m}$ and $>5$ to $>10 \mu \mathrm{m}$. The analysis of the data, shown in Table 1 , revealed the following results: the $>0.25$ to $1 \mu \mathrm{m}$ category represented a $30.0 \%$ in wear particles sample versus an $18.1 \%$ in the bulk particles sample; the $>1$ to $2.5 \mu \mathrm{m}$ group represented a $28.0 \%$ in wear particles sample versus to a $73.5 \%$ in the bulk particles sample; the $>2.5$ to $5 \mu \mathrm{m}$ group represented a $26.9 \%$ in wear particles sample versus to a $8.4 \%$ the bulk particles sample and finally the $>5$ to $>10 \mu \mathrm{m}$ group represented a $15.1 \%$ wear particles sample versus undetected particles in the bulk particles sample.

Table 1. Particles Size distribution in the wear and bulk HCCoCr particles samples.

\begin{tabular}{ccc}
\hline Categories groups: Particles size & Wear particles & Bulk Particles \\
\hline$>0.25$ to $1 \mu \mathrm{m}$ & $30.0 \%$ & $18.1 \%$ \\
$>1$ to $2.5 \mu \mathrm{m}$ & $28.0 \%$ & $73.5 \%$ \\
$>2.5$ to $5 \mu \mathrm{m}$ & $26.9 \%$ & $8.4 \%$ \\
$>5$ to $>10 \mu \mathrm{m}$ & $15.1 \%$ & \\
\hline
\end{tabular}

\subsection{Metallic Particles in MC3T3-E1 Osteoblasts Cell Cultures}

MC3T3-E1 osteoblasts were cultured in presence of different particles concentrations. As an example, Figure 3 shows the invertoscopy images of osteoblast MC3T3-E1 cell cultures in absence of particles (control) in presence of wear particles (central panel) and in presence of bulk particles (right panel). Wear and bulk particles are localized inside the cells where they are stored. As can be observed in this figure, some osteoblastic cells accumulated a considerable amount of particles that end up occupying half of the cell volume. The presence of particles inside the osteoblasts confirmed the suitability of the cell response model to gain knowledge on the cellular events that takes place at the cell-particle interface and in the surrounding of the prosthesis implanted. 


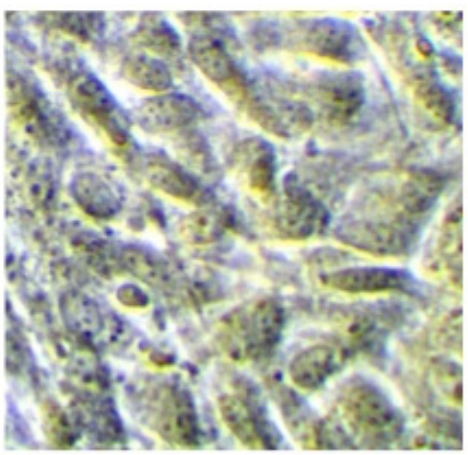

CONTROL

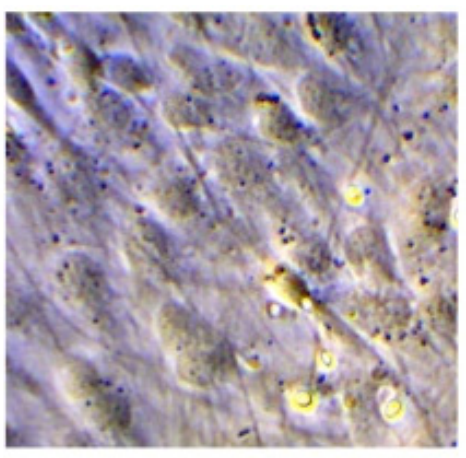

WEAR PARTICLES

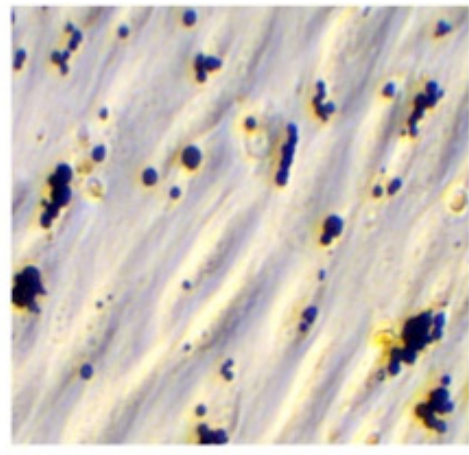

BULK PARTICLES

Figure 3. Invertoscopy images of osteoblasts MC3T3-E1 cell cultures. Osteoblasts were cultured in absence of particles (control), in presence of wear particles $(2 \mathrm{mg} / \mathrm{ml})$ and in presence of bulk particles $(1 \mathrm{mg} / \mathrm{ml})$

\subsection{Effect of Wear and Bulk Particles on the Mitochondrial Respiratory of MC3T3-E1 Osteoblasts: 2D and 3D Cell Cultures}

The effect of $\mathrm{HCCoCr}$ particles on the mitochondrial activity was evaluated by measuring the reduction of the WST-1 reagent (Figure 4). 2D MC3T3-E1 osteoblasts cell cultures were exposed for 72 hours to different doses of wear and bulk particles at the following concentrations: $0,0.5,1$ and $2 \mathrm{mg} / \mathrm{ml}$. The exposure of osteoblast cell culture to wear particles (Figure 4, left panel) produced an increase in the mitochondrial respiratory activity that was dose-dependent on the particles used. A concentration of $2 \mathrm{mg} / \mathrm{ml}$ of wear particles produced an increase of almost 4 folds over the control assay, where cells were no exposed to any particles (Figure 4, left panel). This increase in the respiratory activity produced by the exposure to wear particles could be related to a response of oxidative stress produced by the cells due to the exposure to some metallic alloys (Lozano et al., 2013). In the case of bulk particles (Figure 4, right panel) a comparable increase in the respiratory activity was also observed. Although this increase seems to be also particle dose-dependent, a diminution was observed when cells were exposed to the highest concentration. As the mitochondrial respiratory activity value is directly proportional to the number of metabolically active cells in culture, this result could indicate a toxic effect of the bulk particles at this concentration.

To get a better knowledge of cell response to $\mathrm{HCCoCr}$ particles, a 3D cell culture model of osteoblasts assays was carried out on scaffolds. This cellular model is considered close to tissue architecture (Lee et al., 2009) being suitable to mimic nearly the physiological conditions of bone cells when come in contact with the prosthetic wear debris.

3D osteoblasts cell cultures were carried out on CellCeram scaffolds, a material that was selected due to the fact that presents a composition and a structure similar to bone. Figure 5 shows a cryosem image of a scaffold (panel A) where is remarkable the porosity that presents this material.

The incubation of scaffolds with particles containing solutions showed the presence of HCCoCr bulk particles inside the pores of the foam scaffold structure, as can be seen in the cryosem images of Figure 5 panel B. Osteoblastic cells added to CellCeram scaffolds revealed the presence of cells attached on the scaffold surface. Osteoblasts show a morphology that is representative of this cell line, with an elongated shape and extended filopodia responsible for cells attachment to the scaffold (Figure 5 panels $\mathrm{C}$ and $\mathrm{D}$ ). The results here presented make MC3T3-E1 3D cell culture assay a suitable model for understanding the effect of particles on osteoblast cell response, not only at the interface as happens in the 2D cell model, but when additionally these cells are located in an environment that represent more closely the physiological conditions that appear in the implanted prosthesis. Using this 3D cell culture model, the effect of the metallic particles on osteoblasts respiratory mitochondrial activity were evaluated (Figure 6) and a comparative study between these results and the data obtained in the 2D cell cultures was carried out for the different dose of particles. 

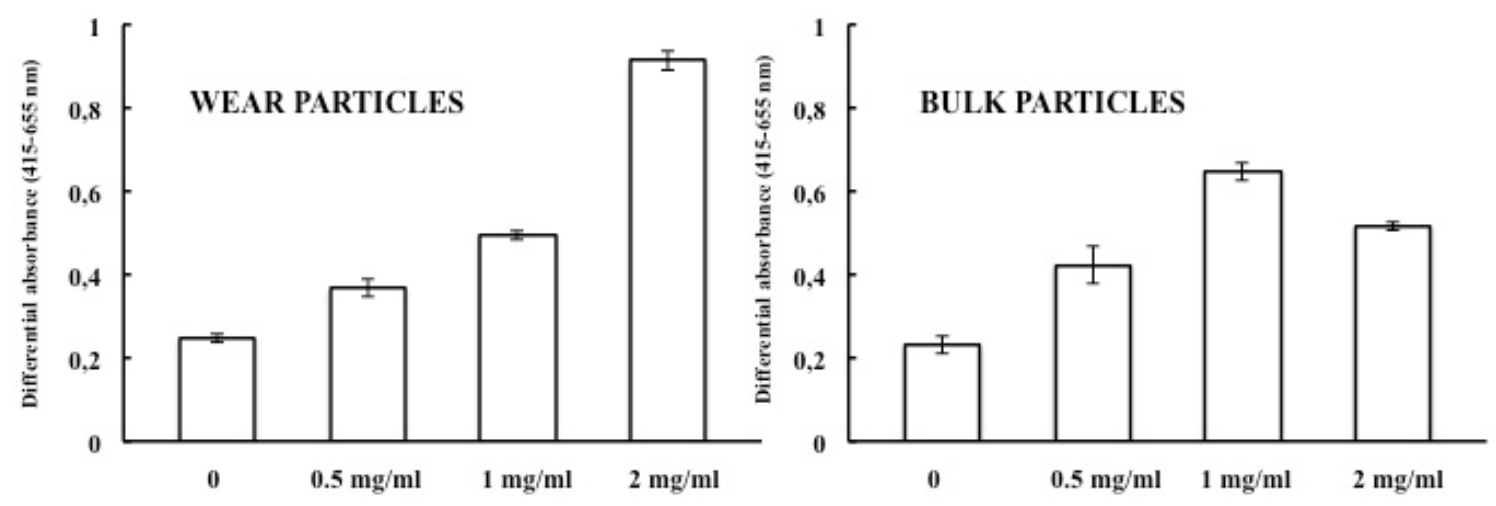

Figure 4. Mitochondrial respiratory activity of 2D osteoblasts MC3T3-E1 cell cultures. Osteoblasts were exposed for 72 hours to different concentrations of wear and bulk particles $(0,0.5,1$ and $2 \mathrm{mg} / \mathrm{ml})$.
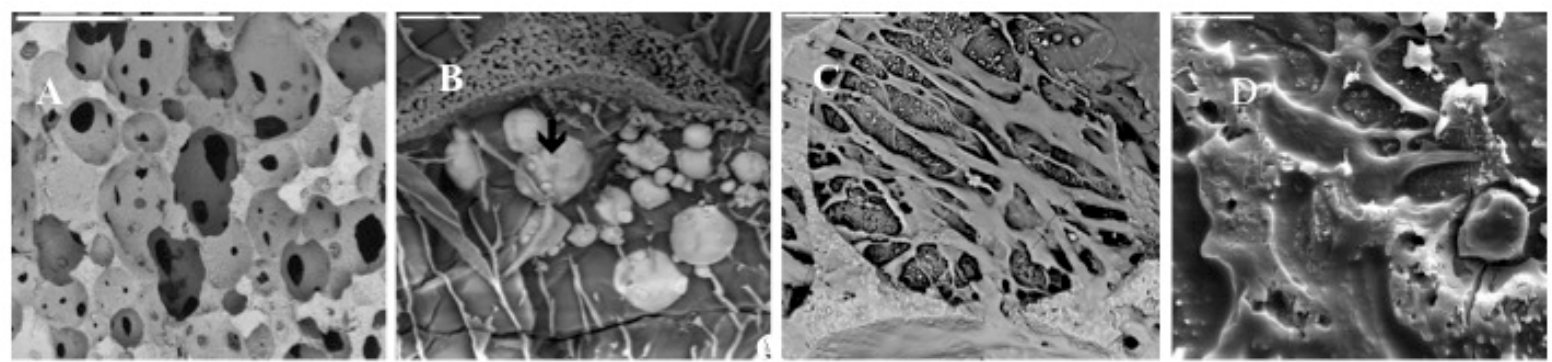

Figure 5. Cryosem images of 3D osteoblasts MC3T3-E1 cell cultures in CellCeram scaffolds. Panel A: scaffold in the absence of cells and particles used as control for 3D osteoblasts cell cultures (scale bar: $1 \mathrm{~mm}$ ); Panel B:

scaffold incubated with bulk particles. Particles with round shape appear inside scaffold labeled with a black arrow (scale bar: $20 \mu \mathrm{m}$ ); Panel C: osteoblasts MC3T3-E1 cells cultured on scaffolds in presence of $0.5 \mathrm{mg} / \mathrm{ml}$ of bulk particles (scale bar: $50 \mu \mathrm{m}$ ). Extended cells' filopodia are observed on scaffold surface; Panel D: detail of osteoblasts cell cultured on scaffold in presence of $0.5 \mathrm{mg} / \mathrm{ml}$ of bulk particles (scale bar: $20 \mu \mathrm{m}$ )
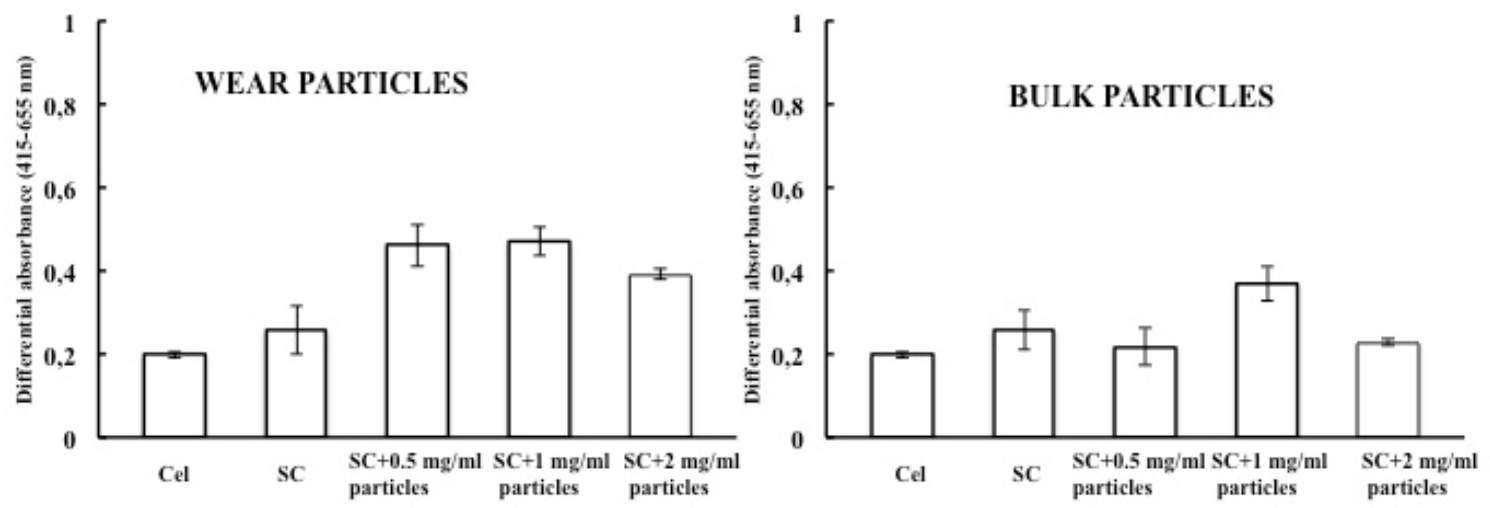

Figure 6. Mitochondrial respiratory activity of 3D of osteoblasts MC3T3-E1 cell cultures. Osteoblasts cultured on $3 \mathrm{D}$ scaffolds (SC) were exposed for 72 hours to different concentrations of wear and bulk particles $(0,0.5,1$ and $2 \mathrm{mg} / \mathrm{ml}$ ). Bar labeled as "Cel”" corresponds to mitochondrial respiratory activity of 2D osteoblasts cell cultures in the absence of particles

As can be observed in Figure 6, the scaffold by itself produces a slight increase in the respiratory mitochondrial activity of the osteoblasts cells that could be interpreted as a minor stress response that could occur as a consequence of attachment of cells to the scaffold. In this 3D model, the presence of wear particles produced a slight increase in the respiratory activity that, at difference of the 2D cell cultures results (Figure 4), does not 
seem a dose-dependent response. In this 3D cell assays, a concentration of $0.5 \mathrm{mg} / \mathrm{ml}$ of wear particles is sufficient to elicit the highest increase in the respiratory activity (almost 2 folds) over the control. This data contrasts with the results obtained in 2D cell cultures, where the enhancement in the respiratory activity reach almost a 4 folds for cells incubated at higher concentration of particles $(2 \mathrm{mg} / \mathrm{ml}$ wear particles) (Figure 4$)$.

The exposure of 3D osteoblasts cultures to bulk particles (Figure 6 right) showed a little effect on the respiratory activity. At a particles concentration of $1 \mathrm{mg} / \mathrm{ml}$ the respiratory activity was 1.4 folds higher than the control value, an increase that was only half of the one observed in the 2D cell culture assay. Concentrations of $2 \mathrm{mg} / \mathrm{ml}$ of bulk particles in this 3D cell culture model produced a decrease in the respiratory activity, as observed before for 2D cell cultures, indicating once again a certain toxicity of this concentration.

\subsection{Effect of Wear and Bulk Particles on Plasma Membrane of MC3T3-E1 Osteoblasts: $2 D$ and 3D Cell Cultures}

To evaluate and quantify the effect of HCCoCr particles on cell death and cell lysis of osteoblasts cell culture, lactate dehydrogenase (LDH) activity was measured in the supernatants as an indicator of plasma membrane damage.

Figure 7 represents the LDH activity in the supernatants of 2D osteoblasts cell cultures that have been exposed to different doses of wear and bulk particles for 72 hours. The exposure of osteoblasts cells to wear and bulk particles produced an increase in LDH activity. The increase in LDH activity seems to be particles dose-dependent in both samples analyzed. A particle concentration of $1 \mathrm{mg} / \mathrm{ml}$ of particles produced the highest LDH increase over the control activity, that reached an increment of 2.2 folds in the case of wear particles and 2.5 folds for bulk particles. No further stimuli in the LDH activity was observed at concentration of $2 \mathrm{mg} / \mathrm{ml}$ with either particles preparation.

LDH activity was also measured in the supernatants of 3D osteoblasts cultures exposed for 72 hours to different concentrations of $\mathrm{HCCoCr}$ particles. Figure 8 shows a clear increase in the LDH activity due to the presence of the scaffold. In addition to the effect of the scaffold, the exposure of osteoblasts cells to wear and bulk particles produced an enhancement in the LDH activity in a dose-dependent manner in the range of concentrations analyzed. This increase is more evident in the case of the wear particles than in bulk particles, where above 0.5 $\mathrm{mg} / \mathrm{ml}$ no increase in LDH activity was observed.

\subsection{Effect of Wear and Bulk Particles on Vimentin Expression in 2D MC3T3-E1 Osteoblasts Culture}

With the aim to study the influence of $\mathrm{HCCoCr}$ particles on osteoblasts cytoskeleton, the expression of vimentin was evaluated in 2D cell cultures in presence of different concentrations of particles after 72-hours exposure. Figure 9 shows the confocal images of osteoblast cell cultures, where cell nuclei, stained with Hoechst reagent, appear as blue fluorescence, and vimentin as green fluorescence.

As it is shown in Figure 9, exposure of osteoblast cells to $\mathrm{HCCoCr}$ particles induced changes in the expression pattern of vimentin. Incubation of osteoblast cell cultures with $1 \mathrm{mg} / \mathrm{ml}$ of both particles samples produced an increased in vimentin levels, that was evident in the case of wear particle samples but limited for bulk particle samples (Figure 9 panels B). Nevertheless, higher concentrations of both particles $(2 \mathrm{mg} / \mathrm{ml})$ produced a reduction in vimentin expression, as confirmed by the attenuation in the fluorescence signal (Figure 9 panels $\mathrm{C}$ ) compared to the increase observed at lower concentration of particles $(1 \mathrm{mg} / \mathrm{ml}$, Figure 9 panels B). This reduction in vimentin expression for the $2 \mathrm{mg} / \mathrm{ml}$ particles concentration seemed less accentuated when osteoblasts were incubated in the presence of wear particles.
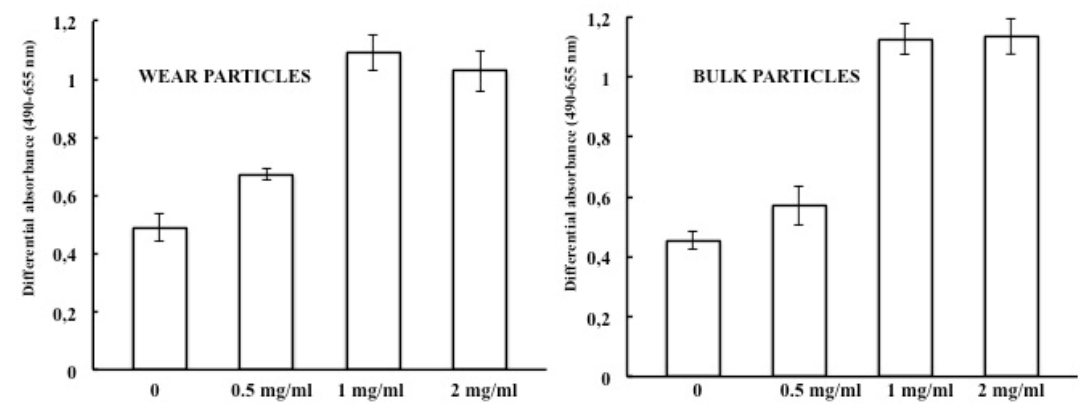

Figure 7. LDH activity measured in the supernatants of 2D osteoblasts MC3T3-E1 cell cultures. Cells were exposed to different doses of wear and bulk particles $(0,0.5,1$ and $2 \mathrm{mg} / \mathrm{ml})$ for 72 hours. 

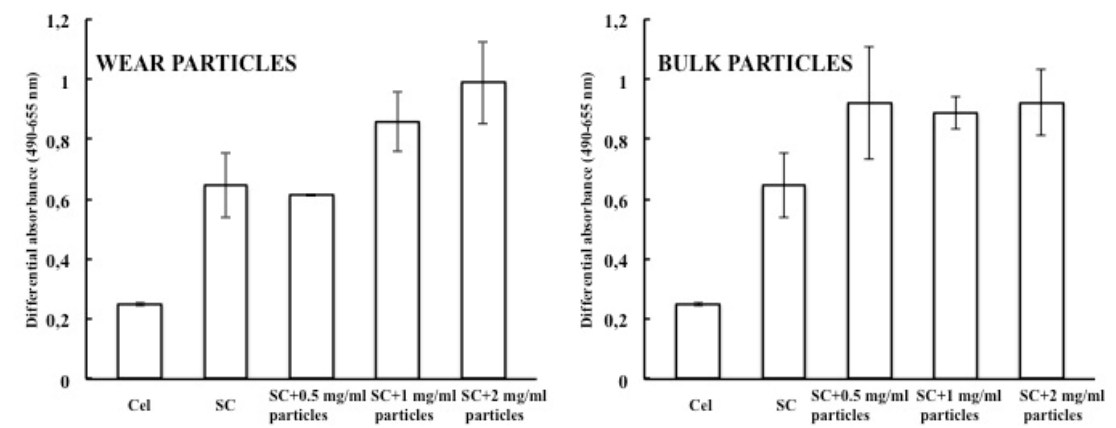

Figure 8. LDH activity measured in the supernatants of 3D osteoblasts MC3T3-E1 cell cultures. Cells were cultured on Cellceram scaffold (SC) and exposed to different doses of wear and bulk particles $(0,0.5,1$ and 2 $\mathrm{mg} / \mathrm{ml}$ ) for 72 hours. Bar labeled as "Cel" corresponds to LDH activity of 2D osteoblasts cell cultures in the absence of particles.

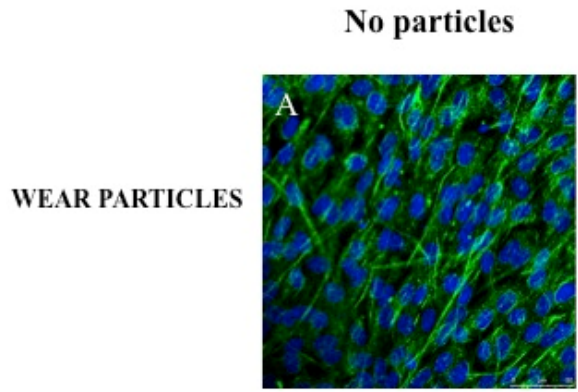

$1 \mathrm{mg} / \mathrm{ml}$
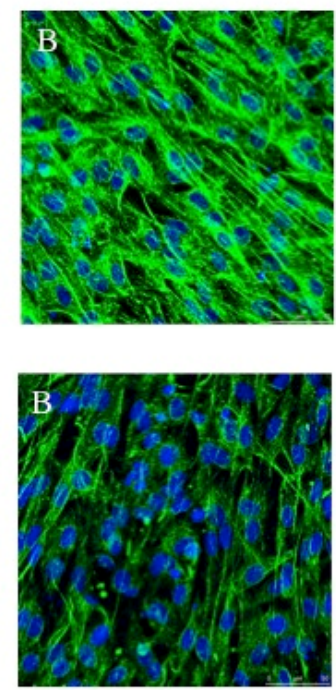

$2 \mathrm{mg} / \mathrm{ml}$
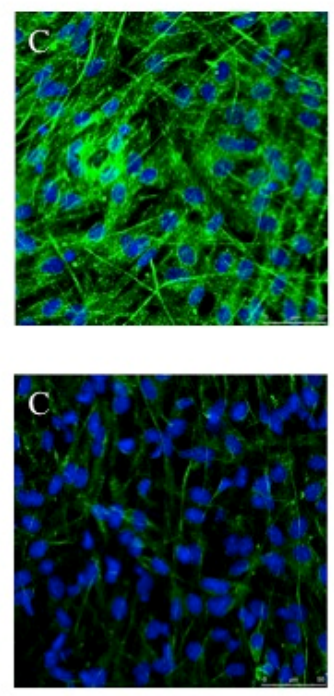

Figure 9. Vimentin expression in 2D osteoblasts MC3T3-E1 cell cultures exposed to metallic particles.

Osteoblasts cultures were exposed for 72 hours to different doses of wear particles (top figures) and bulk particles (bottom figures): Panel A: $0 \mathrm{mg} / \mathrm{ml}$; Panel B: $1 \mathrm{mg} / \mathrm{ml}$ and Panel C: $2 \mathrm{mg} / \mathrm{ml}$. Cell nuclei in blue were stained with Hoechst reagent and vimentin appears in green (scale bar: $50 \mu \mathrm{m}$ ).

\section{Discussion}

Cobalt-chrome alloys $(\mathrm{CoCr})$ are metallic materials commonly used for the MoM hip joints due to their substantially low corrosion and wear rates (Silva, Heisel, \& Schmalzried, 2005; Yan, Neville, Dowson, \& Williams, 2006; Yan, Neville, \& Dowson, 2007). However, particles are still produced as a result of wear and corrosion and this may cause osteolysis and eventually failure of the prosthesis (Billi et al., 2009; Hosman et al., 2010; Catelas et al., 2003). Following implantation, the responses that occur at the interface of a biomaterial and in the surrounding environment are important events in determining the biocompatibility of the implant. When a material is implanted into the bone, a sequence of events takes place including the formation of the bony callus followed by remodeling of this woven bone to lamellar bone (Goonoo et al., 2016). Our understanding of the cellular and tissue responses to biomaterials is still nowadays incomplete. Many factors contribute to the biological response of the tissues to implanted materials and vice-versa. The factors include the site of implantation, the length of contact in the body together with the effect of particles generated due to wear and corrosion processes (Tuan et al., 2008). One major goal is to precisely understand the interaction of wear particles with cells, especially with bone cells during the post-implantation healing period, which is necessary to 
allow bone ingrowth for mechanical stabilization and long-term survivorship of the implant (Hallab \& Jacobs, 2009; Gallo et al., 2002).

Osteoblasts response to particles obtained from a high carbon content $\mathrm{CoCr}$ alloy were here analyzed in 2D and 3D cell culture models (Lee et al., 2009; Huh, Hamilton, \& Ingber, 2011) using two types of particles, one with bulk particles obtained by nitrogen gas atomization, used here as control, and other with wear particles obtained from pin-on-disc corrosion wear test (Chan et al., 1996; Medley et al., 1996; Medley et al., 1997; Medley et al., 1998; Chan et al., 1999). The 2D cell culture allows a closer view of the processes that take place at the biomaterial-cell interface (Fagali et al., 2015), a very important space between cells and material. The 3D cell culture is a model representative of the bone tissue architecture, able to mimic and replicate interactions between cell-cell and cell-extracellular matrix (Lee et al., 2009; Huh, Hamilton, \& Ingber, 2011) therefore representing a suitable model to mimic the conditions that occurs in cells that come in contact with the prosthetic wear debris.

Response to wear and bulk HCCoCr particles in the 2D cell culture osteoblasts-particles interface model showed differences in the respiratory response and in the LDH activity. Both particles samples produced an increase in the mitochondrial activity that can be interpreted as an oxidative stress response (Lozano et al., 2013). Wear particles produced an increase in the respiratory activity that seemed to be directly related to the concentration of particles to which osteoblasts were exposed, a dose-dependence that was no observed for bulk particles where the increase on respiratory activity seemed weakened. Osteoblasts LDH activity was also affected by both particles samples in a certain dose related way. An increase in the activity of this enzyme in presence of particles was observed indicating that both particles samples produced damage on the plasmatic membrane; although a slightly higher damage was induced by wear particles at the lowest concentration tested.

The 3D cell cultures assays showed an attenuated effect of the particles on the osteoblasts mitochondrial respiratory activity compare to the $2 \mathrm{D}$ model. This result might be explained by the binding of some metallic particles and ions to these scaffolds as is reported that hydroxyapatite, the main component of the scaffold and bone, has significant high reactivity with metals (Gutowska, Machoy, \& Machaliński, 2005). This reactivity could cause a diminishing concentration of metallic particles/ion in 3D culture model used that might explain the reduction observed in the mitochondrial respiratory activity in these assays. In any case, the data could indicate that bone hydroxyapatite could function as reservoir of particles generated by wear-corrosion processes. The effect of accumulation of wear-corrosion particles and ions should be considered in bone metabolism and in patient's health.

While LDH activity increased in the 3D osteoblasts cultures (Figure 8), a data that could be interpreted as a signal of a certain damage on the plasma membrane, the scaffold by itself did not seem to have a significant effect in the respiratory activity as no appreciable increase in this activity was detected (Figure 6), making this $3 \mathrm{D}$ model suitable for the study of particles cell response in a cellular model with higher complexity than the $2 \mathrm{D}$ cell culture model.

It should be point out that the observed differences in the osteoblasts response elicited by bulk and wear particles could be to dissimilarities in particles parameters such are: size distribution, shape and composition. Wear particles sample contained a $30.0 \%$ of $>0.25$ to $1 \mu \mathrm{m}$ particles and a $28.0 \%$ of $>1 \mu \mathrm{m}$ to $2.5 \mu \mathrm{m}$ particles meanwhile bulk particles sample contained an $18.0 \%$ of $>0.25$ to $1 \mu \mathrm{m}$ particles and $73.5 \%$ of $>1 \mu \mathrm{m}$ to $2.5 \mu \mathrm{m}$ particles (Figure 2 and Table I). A higher proportion of small particles, with size of $>0.25$ to $1 \mu \mathrm{m}$, observed in wear sample together with differences in shape between samples particles (Figure 1) could also account for differences in cell response. Wear particles showed a snowflake shape with a higher specific area that can contribute to generate more damage to the cell membrane than the round shape particles observed in the bulk sample. It is also important to considerer the composition of both types of particles that could account for the different grade of biological response observed. In this sense, our data show in case of the bulk sample a composition characteristic of the massive material as contains $69 \%$ of $\mathrm{Co}, 29 \%$ of $\mathrm{Cr}$ and $6 \%$ of $\mathrm{Mo}$, while the wear particles have a composition closer to that of the $\mathrm{HCCoCr}$ passive film. SEM/EDS analysis of the wear particles showed the following composition: $26 \%$ of $\mathrm{Co}, 22 \%$ of $\mathrm{Cr}$ and approximately $50 \%$ of oxygen. A significant decrease in the Co content (around $40 \%$ ) and a high increase in the oxygen content with respect to the bulk sample composition were observed, which indicate presumably the presence of chromium oxides particles. Results reported by Catelas et al. (2003) showed that $\mathrm{CoCr}$ wear particles from a metal-metal hip simulator produce particles that do not contain Co and can be the predominant in the wear of metal-metal hip implants. These authors indicate that the chromium oxide particles were produced mostly by wear of the passivation layer covering the implant surface. Doorn et al. (2003) in in vivo assays identified some chromium oxide particles and suggested that $\mathrm{Co}$ may have been dissolved in the tissue environment leaving $\mathrm{Cr}$ and $\mathrm{O}$. Shahgaldi et al. (1995) interpreted the presence of particles with a reduction of proportion of Co to that of the 
original alloy material as an indication of corrosion. Our results reveal that wear particles obtained from the wear-corrosion assays come mainly from the material alloy surface, as their composition is similar to the passivation layer present on the material surface.

A major concern in patients with metallic prosthesis is the description in some cases of the appearance of pseudotumor masses in the close vicinity to the implanted material. It is known that over-expression of vimentin, a protein of the intermediate filament involved in cytoskeleton and cell migration, is involved in tumor processes and in inflammatory response. Our results showed an overexpression of vimentin in osteoblasts MC3T3-E1 cell line in $2 \mathrm{D}$ cell cultures. The extent of vimentin expression seemed to be dependent of the particles samples assayed, as wear particles induced a significant increase in vimentin expression that it was not observed for bulk particles. The overexpression of vimentin in presence of wear particle sample that contains higher proportion of particles with small size and with a particular irregular shape suggest that wear-corrosion products from an implanted prosthesis could be inductive to the formation of granulomatous pseudotumors. This pseudotumors have been described to be generally associated with abnormal high levels of wear (Kwon et al., 2010; Langton et al., 2011) in some patients with metal-on-metal hip prosthesis with a similar prevalence in patients with a well-functioning hip prosthesis and patients with a painful hip that suffer discomfort and develop the necessity to replace the prosthesis by dislocation problems (Kwon et al., 2010). There has been much concerning of reports of local adverse soft-tissue reactions or pseudotumors associated with MoM hip arthroplasty materials that have created a medical alert that justify the research on these materials and their products (Meier \& Roberts, 2011; Meier, 2011). Basic studies focusing on investigating the mechanism by which pseudotumors and tumors are induced after THA ought to deserve more attention together with the application of processes on materials that prevent osteolysis thus down-regulate the overexpression of vimentin and the inflammatory response.

\section{Conclusions}

5.1 Osteoblasts cell response to bulk and wear particles reported here seemed to indicate that the deleterious effects of particles on osteoblasts could have also a relation with the presence of an oxidized layer rich in oxygen as observed in the chemical particles analysis.

5.2 Cell-particles assays reported here strength the utility of the $2 \mathrm{D}$ cell model to study the response at cells-particles interface and the 3D cell model to more closely mimic in vivo conditions.

5.3 Overexpression of vimentin in presence of wear particles suggests that wear-corrosion products from an implanted prosthesis could be inductive to the formation of granulomatous pseudotumors.

Further efforts need to be done in order to apply surfaces treatments to minimize corrosion in combination with other treatments to make materials more resistant to wear and to increase material lubrication that is essential for the appropriate functioning of MoM devices (Liao et al., 2011; Merkle et al., 2010). All aspects in ameliorating material surface could have an effect of lowering the amount of wear particles at the implanted site with a clear benefit for patient health and with a clear and direct impact in the sustainability of the public sanitary system (Arcos et al., 2014). All the efforts make to understand what is producing these reactions and to improve the prosthetic materials are desirable in order to provide the community with more options that may include re-engineered MoM implants.

\section{Acknowledgments}

Financial support was received through the projects MAT2011-29152-C02-02 and MAT2011-29152-C02-01. RMLP and BTPM wish to thank the Ministerio de Economía y Competitividad from Spain for the financial support given by the project: MAT2011-29152-C02-02 and MAT2015-67750-C3-2-R. The authors also wish to thank to Fernando Pinto, who passed away in 2015 and to whom authors want to dedicate in his memory this manuscript, for excellent technical assistance in cryosem microscopy images at Instituto de Ciencias Agrarias (ICA-CSIC) and to $\mathrm{M}^{\mathrm{a}}$ Teresa Seisdedos, $\mathrm{M}^{\mathrm{a}}$ Gema Elvira and Lorena Blanco for excellent technical assistance in Confocal Microscopy at Centro de Investigaciones Biológicas (CIB-CSIC).

\section{References}

Arcos, D., Boccaccini, A. R., Bohner, M., Díez-Pérez, A., Epple, M., Gómez- Barrena, E., ... Vallet-Regí, M. (2014). The relevance of biomaterials to the prevention and treatment of osteoporosis. Acta Biomaterialia., 10, 1793-1805. https://doi.org/10.1016/j.actbio.2014.01.004.

Arnholt, C. M., MacDonald, D. W., Malkani, A. L., Klein, G. R., Rimnac, C. M., Kurtz, S. M., Implant Research Center Writing Committee., Kocagoz, S. B., \& Gilbert, J. L. (2016). Corrosion Damage and Wear Mechanisms in Long-Term Retrieved CoCr Femoral Components for Total Knee Arthroplasty. J. Arthroplasty, 31, 2900-2906. https://doi.org/10.1016/j.arth.2016.05.006 
Billi, F., Benya, P., Ebramzadeh, E., Campbell, P., Chan, F., \& McKellop, H.A. (2009). Metal wear particles: What we know, what we do not know and why. SAS Journal, 3, 133-142. https://doi.org/10.1016/j.esas.2009.11.006

Billi, F., Benya, P., Kavanaugh, A., Adams, J., McKellop, H., \& Ebramzadeh, E. (2012). An accurate and extremely sensitive method to separate, display and characterize wear debris. Part 2: Metal and ceramic particles. Clin. Orthop. Relat. Res., 470, 339-350. https://doi.org/10.1007/s11999-011-2058-9.

Bitar, D., \& Parvizi, J. (2015). Biological response to prosthetic debris. World J. Orthop., 6, 172-189. https://doi.org/10.5312/wjo.v6.i2.172

Catelas, I., Bobyn, J. D., Medley, J. B., Krygier, J. J., Zukor, D. J., \& Huk, O. L. (2003). Size, shape, and composition of wear particles from metal-metal hip simulator testing: Effects of alloy and number of loading cycles. J. Biomed. Mater. Res., 67A, 312-327. https://doi.org/10.1002/jbm.a.10088

Chan, F. W. Bobyn, J. D., Medley, J. B., Krygler, J. J., Yue, S., \& Tanzer, M. (1996). The engineering issues and wear performance of metal-on-metal hip implants. Clin. Orthop. Rel. Res., 333, 96-107.

Chan, F. W., Bobyn, J. D., Medley, J. B., Krygler, J. J., \& Tanzer, M. (1999). The Otto Aufranc Award. Wear and lubrication of metal-on-metal hip implants. Clin. Orthop. Rel. Res., 369, $10-24$.

Doorn, P. F., Campbell, P. A., \& Amstutz, H. C. (1996). Metal versus polyethylene wear particles in total hip replacements. A Review. Clin. Orthop. Relat. Res., 329, S206-S216. https://doi.org/10.1097/00003086-199608001-00018]

Doorn, P. F., Campbell, P. A., Worrall, J., Benya, P. D., McKellop, H. A., \& Amstutz, H. C. (1998). Metal wear particle characterization from metal on metal total hip replacements: transmission electron microscopy study of periprosthetic tissue and isolated particles. J. Biomed. Mater. Res., 42, 103-111.

Doyle, A. Griffiths, J. B., \& Newell, D. G. (1995). Testing for Microbial contamination. In A. Doyle, J. B. Griffiths, \& D. G. Newell (Eds), Cell \& Tissue Culture: Laboratory Procedures (Vol. I: Chapter 7A:1.1-1.9). John Wiley \& Sons Ltd., England.

Fagali, N.S., Grillo, C.A., Puntarulo, S., \& Fernández-Lorenzo, M.A. (2015). Biodegradation of metallic biomaterials: its relation with the generation of reactive oxygen species. In A. Catalá (Eds.), Reactive oxygen species, lipid peroxidation, and protein oxidation (pp. 127-140). Nova Science Publishers, New York.

Figueiredo-Pina, C. G., Matos Neves, A. A., \& Bandarra das Neves, B. M. (2011). Corrosion-wear evaluation of a UHMWPE/Co-Cr couple in sliding contact under relatively low contact stress in physiological saline solution. Wear, 271, 665-670. https://doi.org/10.1016/j.wear.2010.11.014

Gallo, J., Kamínek, P., Tichá, V., Řiháková, P., \& Ditmar, R. (2002). Particle disease. A comprehensive theory of periprosthetic osteolysis: a review. Biomed. Papers., 146, 21-28. https://doi.org/10.5507/bp.2002.004

Goonoo, N. Bhaw-Luximon, A., Passanha, P., Esteves, S. R., \& Jhurry, D. (2016). Third generation poly(hydroxyacid) composite scaffolds for tissue engineering. J. Biomed. Mater. Res. Part B: Appl. Biomater. B, 1-18. https://doi.org/10.1002/jbm.b.33674

Gutowska, I., Machoy, Z., \& Machaliński, B. (2005). The role of bivalent metals in hydroxyapatite structures as revealed by molecular modeling with the HyperChem software. J. Biomed. Mater. Res. A., 75, 788 -793. https://doi.org/10.1002/jbm.a.30511

Hallab, N. J., \& Jacobs, J. J. (2009). Biologic effects of implant debris. Bull. NYU. Hosp. Jt. Dis., 67, 182-188.

Hart, A. J., Satchithananda, K., Liddle, A. D., Sabah, S. A., McRobbie, D., Henckel, J., ... Mitchell, A. W. (2012). Pseudotumors in Association with Well-Functioning Metal-on-Metal Hip Prostheses. J. Bone Joint. Surg. Am., 94, 317-325. https://doi.org/0.2106/JBJS.J.01508

Holzwarth, U., \& Cotogno, G. (2012). Total hip arthroplasty. JRC Scientific and Policy Reports. European Commission. https://doi.org/10.2788/31286

Hosman, A. H., van der Mei, H. C., Bulstra, S. K., Busscher, H. J., \& Neut, D. (2010). Effects of metal-on-metal wear on the host immune system and infection in hip arthroplasty. Acta Orthop., 81, 526-534. https://doi.org/10.3109/17453674.2010.519169.

Huh, D., Hamilton, G. A., \& Ingber, D. E. (2011). From 3D cell culture to organs-on-chips. Trends in cell biology., 21, 745-754. https://doi.org/10.1016/j.tcb.2011.09.005 
Jacobs, J. J., Roebuck, K. A., Archibeck, M., Hallab, N. J., \& Glant, T. T. (2001). Osteolysis: basic science. Clin. Orthop. Relat. Res., 393, 71-77.

Knight, S. R., Aujla, R., \& Biswas, S. P. (2011). Total hip arthroplasty-over 100 years of operative history. Orthop. Rev., 3, e16. https://doi.org/10.4081/or.2011.e16

Kwon, Y. M., Glyn-Jones, S., Simpson, D. J., Kamali, A., McLardy-Smith, P., Gill, H. S., \& Murray, D. W. (2010). Analysis of wear retrieved metal-on-metal hip resurfacing implants revised due to pseudotumours. $J$. Bone Joint Surg. Br., 92, 356-361. https://doi.org/10.1302/0301-620X.92B3.23281.

Langton, D. J., Joyce, T. J., Jameson, S. S., Lord, J., Van Orsouw, M., Holland, J. P., Nargol, A. V., \& De Smet, K. A. (2011). Adverse reaction to metal debris following hip resurfacing: the influence of component type, orientation and volumetric wear. J. Bone Joint Surg. Br., 93, 164-171. https://doi.org/10.1302/0301-620X.93B2.25099

Leandre Casabán, J., \& Igual Muñoz, A. (2011). Influence of microstructure of HC CoCrMo biomedical alloys on the corrosion and wear behaviour in simulated body fluids. Tribology International, 44, 318-329. https://doi.org/10.1016/j.triboint.2010. 10.033

Lee, J., Lilly G. D., Doty, R. C., Podsiadlo, P., \& Kotov, N. A. (2009). In vitro toxicity testing of nanoparticles in 3D cell culture. Small., 5, 1213-1221. https://doi.org/10.1002/smll.200801788.

Liao, Y., Pourzal, R., Wimmer, M. A., Jacobs, J. J., Fischer, A., \& Marks, L. D. (2011). Graphitic tribological layers in metal-on-metal hip replacement. Science, 334, 1687-1690. https://doi.org/10.1126/science.1213902.

Lozano, R. M., Pérez-Maceda, B. T., Carboneras, M., Onofre-Bustamante, E., García-Alonso, M. C., \& Escudero, M. L. (2013). Response of MC3T3-E1 osteoblasts, L929 fibroblasts and J774 macrophages to fluoride surface-modified AZ31 magnesium alloy. J. Biomed. Mater. Res. Part A., 101A, 2753-2762. https://doi.org/10.1002/jbm.a.34579

Medley, J. B. Krygier, J. J., Bobyn, J. D., Chan, F. W., Lippincott, A., \& Tanzer, M. (1997). Kinematics of the MATCO hip simulator and issues related to wear testing of metal-metal implants. Proc. Inst. Mech. Eng., 211, 89-99. https://doi.org/10.1243/0954411971534719

Medley, J. B., Chan, F. W., Krygier, J. J., \& Bobyn, J. D. (1996). Comparison of alloys and designs in a hip simulator study of metal on metal implants. Clin. Orthop. Rel. Res., 329S, 148 -159.

Medley, J. B., Dowling J. M., Poggie, R. A., Krygier, J. J., \& Bobyn, J. D. (1998). Simulator wear of some commercially available metal on hip implants. In J. J. Jacobs, \& T. L. Craig (Eds.), Alternative bearing surfaces in total joint replacement (pp. 92-110). American Society for Testing and Materials, Philadelphia. https://doi.org/10.1520/STP12833S.

Meier, B. (2011). In medicine, new isn't always improved. The New York Times. 26 June, pp. BU1.

Meier, B., \& Roberts, J. (2011). Hip implant complaints surge, even as the dangers are studied. The New York Times. 23 August, pp. A1.

Merkle, A. P., Erdemir, A., Eryilmaz, O. L., \& Marks, L. D. (2010). In situ TEM studies of tribo-induced bonding modifications in near-frictionless carbon films. Carbon., 48, 587-591. https://doi.org/10.1016/j.carbon.2009.08.036

Milosev, I. (2012). CoCr alloy for biomedical applications. In S. Djokic (Ed.), Biomedical applications. Modern Aspects of Electrochemistry (Vol. 55, pp. 1-72). Springer Science+Business Media, New York. https://doi.org/10.1007/978-1-4614-3125-1_1

Mitra, A. (2014). Cell surface vimentin (CSV) redefines CTCs to monitor cancer progression in patients. $J$. Cancer. Prev. Curr. Res., 1, 00014. https://doi.org/10.15406/jcpcr.2014.01.00014

Pourzal, R., Catelas, I., Theissmann, R., Kaddick, C., \& Fischer, A. (2011). Characterization of wear particles generated from CoCrMo alloy under sliding wear conditions. Wear, 271, 1658-1666. https://doi.org/10.1016/j.wear.2010.12.045

Quarles, L. D., Yohay, D. A., Lever, L. W., Caton, R., \& Wenstrup, R. J. (1992). Distinct proliferative and differentiated stages of murine MC3T3-E1 cells in culture: An in vitro model of osteoblast development. $J$. Bone Miner. Res., 7, 683-692. https://doi.org/10.1002/jbmr.5650070613 
Satelli, A., \& Li, S. (2011). Vimentin as a potential molecular target in cancer therapy. Cell. Mol. Life Sci., 68, 3033-3046. https://doi.org/10.1007/s00018-011-0735-1.

Shahgaldi, B. F., Heatley, F. W., Dewar, A., \& Corrin, B. (1995). In vivo corrosion of cobalt-chromium and titanium wear particles. J. Bone Joint. Surg., 77, 962-966.

Silva, M., Heisel, C., \& Schmalzried, T. P. (2005). Metal-on-Metal Total Hip Replacement. Clinical Orthopaedics \& Related Research, 430, 53-61. https://doi.org/10.1097/01.blo.0000149995.84350.d7

Tuan, R. S., Lee, F. Y., Konttinen, Y., Wilkinson, J. M., \& Smith, R. L. (2008). What are the local and systemic biologic reactions and mediators to wear debris, and what host factors determine or modulate the biologic response to wear particles?. J. Am. Acad. Orthop. Surg., 16, S42-S48.

Yan, Y., Neville, A., \& Dowson, D. (2007). Tribo-corrosion properties of cobalt-based medical implant alloys in simulated biological environments. Wear, 263, 1105-1111. https://doi.org/10.1016/j.wear.2007.01.114

Yan, Y., Neville, A., Dowson, D., \& Williams, S. (2006). Tribocorrosion in implants-assessing high carbon and low carbon Co-Cr-Mo alloys by in situ electrochemical measurements. Tribol. Int., 39, 1509-1517. https://doi.org/10.1016/j.triboint.2006.01.016

\section{Copyrights}

Copyright for this article is retained by the author(s), with first publication rights granted to the journal.

This is an open-access article distributed under the terms and conditions of the Creative Commons Attribution license (http://creativecommons.org/licenses/by/4.0/). 